\title{
Autonomous Driving and Urban Land Use
}

\author{
Dirk Heinrichs
}

\subsection{Introduction}

Mobility, transport and land use patterns in urban areas are closely bound up with each other [1]. Urban form plays an important role when households and businesses make mobility decisions, and to a considerable degree dictates transport mode choice. Compact city form with high density and mixed use provide good preconditions for short trips and efficient public transportation, promote walking and cycling, and often render daily car use unnecessary. With sprawling, sparsely populated land uses, on the other hand, walking and cycling are discouraged, while car use is favored. In turn, the availability and use of designated transport modes strongly influences urban form and the necessary infrastructures. The residential suburbanization of the latter half of last century was thus to a great extent encouraged by car availability and the expansion of the transport infrastructure for motorized passenger transport [2].

It is expected that fully automated driving will entail a completely new transport system, which will not only bring with it new possibilities in traffic management, but will also generate completely new types of transport provision that will affect the choice and use of available transport means (see Chap. 12). The idea, for example, that time in a vehicle does not have to be spent on driving-related tasks, but instead permits other activities, may instigate a complete reappraisal of the time factor (e.g. [28]). This ability to attend to other activities in an autonomous vehicle may imply that long car commutes will be considered less a burden than today. This could increase the willingness of households to locate further away from the city center where land prices and rents are lower and where suburban preferences like living in a

D. Heinrichs $(\square)$

German Aerospace Centre (DLR), Institute of Transport Research, 12489 Berlin, Germany

e-mail: Dirk.Heinrichs@dlr.de 
greener environment can be better satisfied. In other words: autonomous driving can potentially alter the trade-offs that households make between choosing location and daily mobility. If we take these connected factors to their logical conclusion, in the end it would be possible to dissolve the time factor as a limiting variable of urban planning. Will the availability of fully automated vehicles then entirely redefine the interrelationship of mobility and urban land use? With few exceptions [3], this question remains as yet untackled. Currently, visions of integrating autonomous vehicles into the urban transport system still essentially refer to the development of vehicle technology itself and the effects on traffic flow.

In light of this, this article's aim is to try to gauge potential urban-structure developments under the influence of a transport system with autonomous vehicles. Equally, it is to identify the way in which political and economic frameworks can influence these developments. The following questions are considered here:

- What future possibilities are conceivable for a transport system transformed, or transformable, by automated driving?

- What effects on urban structures - particularly on their density, mix of uses and layout - might be linked to this in future?

- What influencing factors are particularly significant in developing a transport system with automated cars in cities?

- What aspects should definitely be incorporated into the debate on autonomous driving from the urban planning and development perspective? Also, though: In what way should the discussion on the development of cities take up the subject of "the automation of transport"?

As a basis for the examination of these questions, this article will evaluate currently available scenarios on the city of the future. The following Sect. 11.2 introduces the scenarios and visions of "the city of tomorrow" available in the literature, and their ideas regarding the integration of autonomous vehicles into transport systems. It will then describe what different future possibilities can be conceived for a transport system that is transformed, or transformable, by automated driving, in which urban structures they can develop, and which essential influencing factors are essential for this development.

Building on this, Sect. 11.3 contains a close analysis of the possible "fully automated" transport system of the future, based on two idealized scenarios developed by the authors. At the core of these scenarios are (a) autonomous private vehicles, and (b) autonomous vehicles as an integral part of public transport. Based on a short characterization of both scenarios, we analyze what the future effects of each scenario on urban structures might be.

Section 11.4 discusses what factors might be especially significant in developing a transport system with automated vehicles in cities. We will identify the driving forces for the scenarios under examination.

The concluding Sect. 11.5 summarises the essential findings. It outlines what aspects definitely should, from an urban planning and development perspective, be brought to the debate surrounding automated driving, but also asks how the discourse on urban development and planning should embrace autonomous driving. 


\subsection{Autonomous Driving as a Feature of City-of-Tomorrow Scenarios}

As automated driving in cities has not yet become reality, and the effects on urban structures are thus not yet observable either, scenarios offer one possibility of drawing on conceivable future developments and their interrelations. Scenarios describe both a potential future situation and the development of the path leading from today into the future $[4,5]$. They are a recognized instrument for uncovering and structuring changes, their drivers and consequences, in a partly unknown, uncertain and rapidly changing environment [6].

For the following account, a systematic analysis was carried out of the available literature on the city of the future that deals with the development of mobility and transport. From the full range of studies, a selection of core documents and scenarios contained therein were considered for a more detailed analysis. They met the following criteria: a traceable account of set objectives, their status and a development path; the identification of driving forces and their interdependencies; and a treatment of the topic of mobility and an account of its interrelationship with settlement structure. Finally, these documents were grouped according to similarity of type. We then analyzed the forms and significance of automated driving they describe, and the changes that significantly impact this trend. The classification proceeded along two axes of uncertainty which are particularly relevant when examining automated driving: the availability and integration of intelligent communications infrastructure (low or high), and the acceptance and use of this infrastructure in general, and for mobility, by the urban population (characterized as fragmented/low, or high).

The scenarios described in core documents can essentially be classified into three types:

- The regenerative/intelligent city

- The hypermobile city

- The endless city

These scenarios will be described more closely below.

\subsubsection{The Regenerative and Intelligent City}

A series of future studies have highlighted the development of so-called regenerative cities as a possible development path [7-12]. These studies view technological developments that use resources in an efficient and environmentally friendly manner as being the heart and driving force of urban development from 2030 to 2050. At their center is energy-related building conversion (solarization, energy-plus houses) and the increasing use of locally generated power from renewable sources, which is distributed and shared over so-called microgrids or peer-to-peer power systems. This is supported by intelligent control mechanisms which allow a link-up with other areas of urban functions, such as 
mobility. The significance of intelligence and information is highlighted in the corresponding studies. They describe the transformation into a technological regime that is no longer characterized by technologies for individual sectors (energy, transport, waste etc.) but rather guarantees a high level of integration between sectors.

This technological development is accompanied by a transformation in the behavior of the urban population [7]. In general, sustainable consumption is assumed as a very conscious and responsible way of dealing with resources [9]. This is explained by the consuming urban population having a greater wish for well-being and quality of life in future, which are defined differently to economic well-being. Society will accept energy-optimized, and sustainable mobility because the majority of the population not only has its advantages presented to them in the media, but can also experience them in daily life.

The key to this lies in densely populated metropolitan areas, in which a wide range of integrated but simple and affordable mobility provision is assured. Cities are characterized in this scenario as places that, due to their density, allow efficient use of resources. To this is added the assumption that, with the growing significance of cities as economic and social centers, the potential of taking decisions and action at city level will increase in future. A number of the studies we analyzed state that cities such as London have already demonstrated the possibility to transform urban infrastructure, and implement decentralized, innovative approaches to energy and waste, without needing national policy. Cities transform themselves, driven by competition (between cities), policy and city government, which actively seek to improve the qualities of the location.

In the course of the resource-efficient transformation of the city, the conditions of mobility in the regenerative and intelligent city also change. Information and communication technology is becoming increasingly pervasive in the transport system. The studies analyzed see in this a basis for expanding demand-oriented mobility-management approaches, and the linking of transport provision with a flexible, multimodal transport system in the future (see Chap. 9). Public transportation's role as the backbone of urban mobility is being further expanded and continually modernized, for example in integrated planning, with walking and cycling as part of ecomobility, whose share of road space is increasing. Supplementing this, citizens also have individual transport modes at their disposal (bicycles, e-bikes, electric cars and transporters), indeed precisely when and where needed by an individual ("mobility on demand"). This "sharing" provision, following the principle of "using not owning," is being introduced and extended by various providers and helps to greatly reduce the amount of public space currently taken up by private cars. A personal, mobile and electronic mobility assistant allows all the available means of dealing with daily mobility to be weighed up, and situation-specific optimal variants to be selected.

One topic of the studies is the further development of electronic assistance systems for cars, in conjunction with the development of new, more efficient drive types. It is assumed that privately owned cars will also continue to have some significance in future [11]. Various studies expect vehicles, with electronic assistance systems for semi-autonomous 
use fitted as standard, to be present in the period 2030-2050. On freeways with high transit volumes or on commuter routes, for example, they allow driving on autopilot, which optimizes the traffic flow. This is assured through high-level interconnectedness and communication between vehicle and the transport infrastructure. This development will be enabled by new legislation regarding licensing, insurance and liability, as well as a range of acceptance-generating concepts from the state concerning data management and standardization (open source, interface compatibility, data protection and security).

As part of the changes in mobility provision, the studies we analyzed also describe a transformation in cities' urban spatial structure. The interlinking of transport provision, according to these authors, increases the formation of so-called mobility hubs, which can already be seen today. It is assumed that city districts will be organized around these hubs in a polycentric urban structure in future. Land consumption for parking spaces in urban areas will have clearly fallen. The reasons for this are a dynamic distribution of vehicles in city districts, and automated, space-saving "parking racks."

\subsubsection{The Hypermobile City}

The hypermobile city, as a potential development path, is a particular focus in a study by the Foresight Directorate of the UK Office of Science and Technology [7]. It outlines the development of a society, up to 2055, in which uninterrupted information, consumption and competition are the norm [7].

This scenario, like that of the regenerative city, also assumes that any remaining barriers to the majority of society using individual transport will be overcome, but with continued very high demand on resources and the corresponding environmental consequences. One essential element and driver of this growth is acceptance of the development of electronic and digital infrastructure. This could involve using cameras for virtual exchange, for example, or personal information assistants. If acceptance is currently still low, it will markedly increase in coming years due to its commercial and lifestyle advantages. People in the city of the future will be "always on," whether at home or work. To manage this, they will use personalized assistants equipped with encryption technology to help them in extensive organizing and daily planning. Even if the problems and reservations regarding data protection and privacy are clearly highlighted issues in this scenario, in the end they will be put to one side due to the benefits electronic assistants bring to users.

Between now and 2055, the state and private sector will have cooperated on developing the required technologies. Key interventions include strong support of user-related information and communications technology (personal assistant systems, standardization of communication standards, and GPS) and technological development (encryption technology, sensors, position finding). One important prerequisite on the way is putting great effort into data security at the European level. 
Mobility in this scenario's target year is described as markedly networked. The authors outline a development in which mobility demand continues to rise. The strong emphasis on information and communication technology in this scenario will also further mobility's automation, not least in optimizing traffic flows and reducing jams. In cities, mass taxi systems will to a great extent replace standard public transportation. These will take over the job of efficiently carrying and picking up passengers in boarding zones. The vehicles used locally for this will operate in assigned districts, and users will call them up using their personal assistants. The network will compute the most efficient route, including picking up and dropping off other passengers, and calculate the price. This network, also known as a "swarm," can process large volumes of data on the traffic situation and demand locations. The vehicles can adjust their route. Passengers can use any vehicle instead of having to wait for a certain line.

Autonomous vehicles will travel long-distance on freeways on "guided lanes" that are specially reserved for autonomous vehicles, some of them also for overnight use. People will buy larger vehicles and drive longer distances. These vehicles will be equipped with an "on-board driverless unit," which communicates with automated systems along freeways and essential commuter routes. This produces convoys of automatically controlled vehicles travelling tightly together at high speed.

The development of urban land use is described differently in this scenario. On the one hand, there will be highly condensed city centers; on the other, suburbs with lower densities will grow. While young people in particular will prefer to live in urban centers, a growing number of high-income households will decide to move to city peripheries or the country. Despite increasing distances to their jobs in the city center, they will be able to continue having intensive working lives, either by aid of telepresence-using ever-more-powerful communication instruments - or the convenient use of automated vehicles. At the same time, this population group, by living in suburbia, will feel they have the opportunity to recover from increasingly tiring and demanding working lives in the hypermobile world.

\subsubsection{The Endless City}

While the scenarios for regenerative and hypermobile cities highlight technological development as a motor for changes in city life, mobility and urban structures, this scenario paints a somewhat different picture [12].

The underlying assumptions here are that technological innovations are not taken up to any great extent, particularly due to the high cost of the necessary infrastructure. Technological development does take place, but is mainly restricted to efficiency gains in specific areas (combustion engines, solar energy). The power of the state to steer development is seen as limited. Even a transformation in behavior, as sketched out in the developments above, will not be seen. 
With regard to mobility and urban structure, this scenario's authors envisage a model still clearly dominated by cars. Due to limitations in how much states can develop public transport systems, so-called informal paratransit services will continue to grow. The degree of networking with available provision will remain low. The potential for autonomous driving systems is not discussed. Spatially, cities will exhibit low density and fragmented settlement structures. In this regard, the authors are extrapolating a trend that is currently observable globally [13].

\subsubsection{Discussion}

The selection and analysis outlined above shows that, scenarios do partially discuss the possibility of a transport system that is changed, or capable of being changed, by automated driving. Automated solutions are formulated in scenarios with a high penetration and interlinking of innovative communication and navigation technologies in particular (regenerative and hypermobile cities). Here, automated driving is expected to contribute to public transportation. The scenarios describe the use of stackable and programmable compact cars, for example, and a networked mass taxi system. Automated private vehicles are mentioned in the course of long-distance freeway travel. Table 11.1 summarizes the main characteristics of the different scenarios with respect to likely forms of autonomous driving, the implications on urban form and land use, and the main driving factors.

Turning to the effects of automated driving on urban structures, the various scenarios first describe how it is bound up with an overall transformation in the general framework. The regenerative city scenario assumes an increasing density of population and functions in cities. Other scenarios (hypermobile and endless cities) presuppose a continuation of the suburbanization tendencies that can currently be seen around the world. These are viewed as the consequence of high-income househoulds' individual preferences, or as being due to processes of pushing low-income households out of cities. The formation of so-called mobility hubs or nodes is described in various scenarios as a visible change in urban form resulting from a transport system with elements of automated driving. In the regenerative and intelligent city scenario, the idea of networking is rigorously carried over to urban space. Multi-modal transport hubs allow physical networking and simple transfers between modes, e.g. from (electric) car to public transport. The scenario goes one step further, in that it also assumes a change in other uses, stemming from the bundling of different mobility options. It describes city districts that are organized around mobility hubs and utilities, and in which automated vehicles are incorporated as part of the public transport fleet. Parking and its connection to urban space is also discussed in very different ways in almost all scenarios. The regenerative city scenario describes the drop in land consumption in conjunction with falling numbers of private cars and local parking-area management. In the intelligent city of the future, an interlinking of private-car use with public transport will have been achieved, and new park and ride areas will have emerged at mobility hubs. 
Table 11.1 The scenarios in overview

\begin{tabular}{|c|c|c|c|}
\hline Scenario & $\begin{array}{l}\text { Form of autonomous } \\
\text { driving }\end{array}$ & Urban land use & Driving factor \\
\hline $\begin{array}{l}\text { Regenerative } \\
\text { city }\end{array}$ & $\begin{array}{l}\text { - Flexible, multimodal and } \\
\text { networked public } \\
\text { transport system as the } \\
\text { backbone of urban } \\
\text { mobility } \\
\text { - semi-autonomous cars } \\
\text { (autopilot) on freeways }\end{array}$ & $\begin{array}{l}\text { - Formation of } \\
\text { intermodal mobility } \\
\text { hubs } \\
\text { - Reduction in land } \\
\text { consumption for urban } \\
\text { parking spaces due to } \\
\text { new parking systems }\end{array}$ & $\begin{array}{l}\text { - Technological } \\
\text { development (in the } \\
\text { energy system) } \\
\text { - Conscious and } \\
\text { responsible use of } \\
\text { resources } \\
\text { - Legislation and } \\
\text { acceptance promotion by } \\
\text { the state }\end{array}$ \\
\hline $\begin{array}{l}\text { Hypermobile } \\
\text { city }\end{array}$ & $\begin{array}{l}\text { - Highly networked } \\
\text { (autonomous) mass taxi } \\
\text { systems } \\
\text { - Autonomous cars on } \\
\text { freeways with high } \\
\text { transit volumes or along } \\
\text { commuter routes, on } \\
\text { reserved "guided lanes" }\end{array}$ & $\begin{array}{l}\text { - City centers of high } \\
\text { density } \\
\text { - Growth of low-density } \\
\text { suburbs }\end{array}$ & $\begin{array}{l}\text { - Increasing acceptance of } \\
\text { information and } \\
\text { communications } \\
\text { technology due to its } \\
\text { lifestyle and commercial } \\
\text { benefits } \\
\text { - Cooperation of state and } \\
\text { private sector in } \\
\text { developing the necessary } \\
\text { ICT technologies }\end{array}$ \\
\hline Endless city & $\begin{array}{l}\text { - Predominantly } \\
\text { car-dominated } \\
\text { - Low level of networking } \\
\text { with public transport } \\
\text { (high proportion of } \\
\text { informal "paratransit" } \\
\text { provision) } \\
\text { - No notable } \\
\text { developments in } \\
\text { automated driving }\end{array}$ & $\begin{array}{l}\text { - Suburban growth } \\
\text { - General decline of } \\
\text { settlement densities }\end{array}$ & $\begin{array}{l}\text { - Limited state power to } \\
\text { steer development } \\
\text { - Technological } \\
\text { development restricted to } \\
\text { efficiency gains in } \\
\text { discrete areas }\end{array}$ \\
\hline
\end{tabular}

Author's own description, based on [7-12]

The descriptions of intelligent and regenerative cities in particular are thus characterized by a basic conviction that technology will overcome existing and foreseeable problems (scarce resources, environmental change). The central significance of technological development is also confirmed in the endless city scenario, but from the opposite point of view. There, lack of innovation is interpreted as explaining a series of negative developments. In a certain sense, this scenario depicts possible developments in southern cities of the globe, where the capacity of the state to direct development is comparatively low.

Only the hypermobile city scenario critically deals with the topic of data. Problems of data protection and security are taken to be accepted in the target period of 2055, as the individual benefits of information and communications solutions for participation in social networks and working life outweigh the disadvantages in the eyes of the population. 


\subsection{Autonomous Driving and Its Impact on Urban Structure}

The scenarios described in the previous section propose answers to the question: In what form is automated driving conceivably a feature of tomorrow's cities' transport systems? We will now have a closer look at the possible changes in urban form and land use resulting from this: How will the distribution of uses, density, and layout of urban spaces change under the influence of autonomous driving?

The scenarios introduced above demonstrate that fundamentally different options can be imagined. Firstly, they describe the development of autonomous private vehicles that, depending on the scenario, are controlled with no external aids by an autopilot system or are integrated into the traffic flow via vehicle-infrastructure communication. Secondly, the scenarios envisage autonomous driving as an integrated part of public transport provision. It can be assumed that the effects on urban form could differ greatly depending on the form of autonomous transport system. In the following, therefore, both forms are considered separately.

\subsubsection{Autonomous Private Cars}

At its core, this form describes the transfer of driving tasks to machines in uni-modal individual transport. It calls on aspects of the use cases, outlined in Chap. 2, of freeway pilot, fully automated with extended availability through driver, and valet parking.

This case assumes that future use will largely correspond with today's car usage. Apart from the changed properties of the technology used, no changes are expected. Cars will still be in individual ownership. No assumptions are made concerning changes in modal and destination choice patterns. There are, however, changes regarding current vehicle use. First, autonomous driving permits other activities during the trip: Former drivers will, for example, be able to work on their laptops, eat, read a book, watch a film or call friends [14]. Second, autonomous driving will change access and egress. Today's cars are either driven directly from home to the destination, or the user has to walk to the parking location of the vehicle at the start of the trip and again from the parking to the final destination. One impact of autonomous driving, however, will be that these distances before and after the main journey will be made by the car, not the driver. The driving robot will maneuver the car from its original parking space to the location of the owner/user and, after arriving at the destination, to an allocated parking space.

The possible effects and changes on urban structure from autonomous-vehicle usage include, firstly, the parking area needed for vehicles at home and destination. Secondly, locations would become more attractive for households choosing places to live. There will also be a transformation in the attractiveness of locations that are destinations for daily activities, such as shopping and leisure. This is accompanied by changes in the space required for flowing traffic resulting from autonomous car use. These three aspects will in the following section be looked at more closely. 


\subsubsection{Change in the Required Parking Area}

Overall, the expected changes in the area required for home parking are small, although they differ according to type of settlement structure. In residential neighborhoods of single-family houses, where parking spaces are on the same plot as the home, no changes are expected. The available parking space will simply be occupied by a different (autonomous) vehicle. In areas of higher density, such as inner-city districts, it may be assumed that neighborhood parking zones or collective garages will appear or be developed, as only in this way will autonomous vehicles be guaranteed to find a space in the neighborhood-defined catchment area.

Further effects of autonomous driving on parking areas are possible at journey destinations away from home. This includes trips made for shopping, leisure and work. An autonomous vehicle would be able to drop off its passengers at their destination and then independently park itself in an allocated parking space or a collective garage. It is also assumed here that sufficient parking capacity will be provided to allow vehicles to find a space safely and reliably. On the one hand, this use of autonomous driving, where the vehicle drops the user off at the destination and proceeds to park autonomously, may be accompanied by greater user willingness to visit certain destinations by car. Equally, there may be a substantial impact on the provision and management of parking areas. Particularly in areas of high-usage density, it may be assumed that a bundling of parking provision, in the form of collective garages, will follow.

The possibility of saving space is named as an essential argument for the use of automated parking systems. These should be made more space-efficient, primarily by replacing ramps and aisles with lift shafts, and lowering storey heights, but also by increasing parking density $[14,15]$. The developers reckon on up to $60 \%$ more parking spaces on the same area by using parking robots [16].

The efficient use of space for parking is especially attractive in terms of costs [16-18]. Parking spaces required for building developments consume a lot of space and represent a considerable share of the costs of the whole investment, particularly when the garage to be built is not at ground level. There have already been some projects testing parking in garages with autonomous vehicles $[19,20]$. The driver hands the vehicle over at the garage entrance. The parking function is activated with a smartphone app. The car receives the route data to the nearest available space from a central garage computer via WLAN and drives to it autonomously. An automatic parking system already in existence may serve as an example. All necessary vehicle movements, except for entry and exit into a handover booth, are carried out automatically (via conveyors and shifting equipment) or with a specially developed parking robot, as is already in use [16].

As mentioned above, the restructuring and possible concentration of parking areas might not take place everywhere. It will primarily be restricted to areas which are especially attractive destinations, and where costs for building the required parking lots, and therefore also the attractiveness of space-saving solutions, are particularly high (the high price and scarcity of land resulting in multi-level solutions). High-density city center service and shopping zones count among these areas, as do new business districts with a 
high number of workers. To this may be added mobility hubs such as airports and railroad stations, where, on top of the criteria just given, safe and secure solutions for long-term parking are sought. The extent to which the costs of parking might change in the course of autonomous driving cannot be estimated. On the one hand, dropping off passengers at the destination and subsequently parking elsewhere in the city (with less pressure on use and therefore cheaper) may save money [21, 22]. On the other hand, retrofitting and restructuring parking facilities and infrastructure brings with it its own costs.

\subsubsection{Change in the Attractiveness of (Residential) Locations}

Some studies point to an increasing attractiveness of suburban residential districts when autonomous driving becomes available [2, 22, 23]. According to this argument, households using an autonomous vehicle may choose to live in green areas with lower house prices, but further from the city center, as the autonomous vehicle will compensate for the location's downsides (longer distances). One consequence may be that new residential areas of relatively low density spring up, similar to the development of suburbanization in the second half of the last century. That was strongly driven by motorization, infrastructure, a planning policy approach of separated uses and dispersed cities, and households deciding to settle in the countryside. The results are still to be seen in today's land use patterns [24].

In general, it is known that working people's choice of where to live is far more influenced by factors such as quality of life and living environment than the wish to be near to their place of work [25]. This is backed up by a relatively high prominence of commuting to work. Some $60 \%$ of all employees subject to social insurance in Germany, that is around 17 million people, do not work in the municipality in which they live. In order to get to work, working people spend on average around half an hour each way. Car use dominates here, being used to make $66 \%$ of trips [26], in the USA as many as $86 \%$ [27]. Based on datasets covering employment and occupation, as well working across regional borders, Guth et al. [25] discovered that the proportion of commuting beyond the home municipality, and distances covered, have grown in German areas of agglomeration in the last decades.

Autonomous driving could further encourage this trend and the willingness to accept longer commutes. First, it is assumed that an increase in travel comfort will accompany autonomous driving (e.g. [14]). The travel time will no longer have to be taken up paying attention to the onerous task of driving, but will instead permit other activities. Mobility will not necessarily be seen as an unpleasant obligation or loss of time. Moreover, travel times may get shorter. In connection with autonomous driving, there are high expectations for a generally more efficient handling of flowing and stationary traffic [2, 22, 28]. Autonomous vehicle can harmonise their driving with each other, for instance when accelerating or braking, thus reducing journey times. Close to zero waiting at junctions is also forecast [14]. Clear time gains will also come when looking for parking spaces, as passengers are set down first. Overall, a journey with an autonomous vehicle will be easier 
to predict and plan and be more reliable in terms of time. This is the result of almost constant speeds and a reliable and predictable routing from starting point to destination.

Improved travel comfort and shorter and more reliable travel times are relevant factors for households weighing up further-away jobs, or other objectives such as good schools, against other location criteria such as local house prices or the attractiveness of a country location. The basis for decision-making could change, especially for working commuters with an autonomous vehicle. Journey times are a particularly large additional burden for commuters [29]. This is further exacerbated where it becomes impossible to calculate durations, and thus the time of arrival at the destination. Psychological studies for Greater London [30] show that time losses that the transport user cannot control-in traffic jams, for instance - are responsible for stress to a particularly large degree.

\subsubsection{Space Requirements for Flowing Traffic}

The benefits of autonomous driving mentioned above also lead to expectations that capacity on transport routes will be freed up. Coordinated acceleration and braking, and the higher vehicle frequency (the so-called "platooning") will make possible a reduction of the street area used for traffic [30]. A substantially higher vehicle density in relation to road area is to be expected [30,31], although forecasts for the extent of this increase in capacity differ. Fernandez [31], for instance, assumes up to $500 \%$. Brownell estimates over $250 \%$ for highways and some $180 \%$ for inner-city streets [32]. This means that the area required for flowing traffic could be reduced, by reducing the number of traffic lanes, for example. Lane width could also be cut in comparison to the present size, due to the altered driving behavior of autonomous vehicles (see Chap. 16). The reduction in the space needed for flowing traffic could allow other uses to be encouraged, such as cycle lanes and footpaths. Various authors, however, indicate that such effects only come into play with full automation [22].

Higher density of flowing traffic could also have an impact on transport users such as pedestrians and cyclists in other ways. Segregation effects may increase, for example, and crossing the street with densely flowing traffic may be made more difficult. In order to guarantee the benefits of autonomous driving for traffic flow while simultaneously maintaining its "permeability" for pedestrians and cyclists, the installation of intersection-free crossings such as under and overpasses would be a necessary consequence.

\subsubsection{Autonomous Taxis as an Integrated Part of Public Transport}

A second development, far more prominently discussed in the scenarios in question, is the emergence of a new model of urban mobility, in the form of autonomous taxi fleets. This touches on aspects of the "Vehicle on Demand" use case as described in Chap. 2. In such a system, low-cost autonomous taxis do not operate on fixed routes following rigid timetables, but rather in a demand-oriented and flexible way. They are in permanent 
operation and run in a city-wide, dense network of stations. This mode of operation is similar to hailed shared taxis. The city is divided into cells. A "central transit point," or a series of them, for pick up and drop off belongs to each of these cells. It should be possible to integrate and combine taxis with rail-bound public transport. The taxis will take over feeder and dispersion functions to and from rail-based public transport stations and pick up passengers there, while the more efficient and potentially faster public transport takes over for longer route sections. The use of an automated taxi network has already been described and modeled as a concept [32-34]. It could lead to a fundamental transformation of public transportation and solve the problem that high-speed rail has covering the last mile [23]. It involves abolishing standard bus and tram stops. It is important that the system is an integrated one. It is an open question whether taxis will be operated by the public or private sector.

\subsubsection{Public Space Used for Transport and Parking}

The effects of a public transport system with autonomous vehicles on urban land use could be very extensive. The use of autonomous vehicles could cut down the number of parking spaces in city centers considerably, as the vehicle would not have to navigate to a parking station some distance away, but would simply drive to the next passenger. Vehicles would thus be in continuous service. Demand for parking spaces would fall. It would, though, be necessary to set up local depots for the cleaning, maintenance, refueling/charging and repairs of vehicles in service.

Permanently available deployment of such taxi fleets may strengthen carsharing, and possibly dynamic "ridesharing" as well, as it allows the spontaneous renting of a vehicle, calculated to precise minutes and distances, for door-to-door journeys [14]. It could be viewed as a logical extension of currently available flexible car-sharing business models, which already have these properties (Car2Go, City Car Club, DriveNow, Zipcar). In this light, it may be assumed that such a system would noticeably alter vehicle ownership and usage (see Chap. 9). An increased degree of occupancy in car usage is also possible [22].

One consequence that may be assumed is a drop in car ownership among households living in areas with such a mobility-on-demand service in operation. Americans, for instance, could currently imagine getting rid of their second car, given the availability of such a system with direct pick-up from the front door [28]. The change in car ownership would lead to a change in the parking space needed for stationary traffic. This may go as far as stationary traffic largely disappearing in favor of areas for multi-functional trips. These areas could be wider than before and be divided into lanes for bicycles and electrically aided micro-vehicles with speeds of up to around $30 \mathrm{~km} / \mathrm{h}$, with a further lane for heavier and faster vehicles.

A further change in the use of urban space is the establishment of pick-up and drop-off stations, which will further enhance the character of mobility hubs, especially those with transfer points to other forms of public transport. Beyond the reshaping of these spaces (stopping/short-term parking, picking up of passengers), changes in usage can also be 
expected, such as a greater concentration of "traditional" shopping and service facilities at the hubs.

Through the extensive reshaping of the public transport system, an impact on the complementary public transport infrastructure and uses is also possible. If users convert from using private cars to autonomous taxis linked up to an efficient rail-based network, forming the "backbone" of the system, passenger numbers would increase on these routes and, in all probability, capacities would have to be adjusted.

\subsection{Essential Driving Forces for the Development of an Urban Transport System with Automated Vehicles}

The previous Sects. 11.2 and 11.3 analyzed the scenarios in question and, based on the different characteristics, discussed the impact of a transport system influenced by autonomous driving on urban land use. Following this up, this section asks which factors could have the greatest impact on the development of this type of system.

The discussion of the scenarios firstly shows the great importance of technological innovation, where autonomous driving obtains an increasing role in the transport system. Progress and new developments in the area of information and communication technology, electronic and digital infrastructure, data management, and artificial intelligence are essential drivers of this trend, whereby a transport mode's automation can be viewed as part of a more extensive automation of urban processes in general. The automation of parking, or of energy and facility management, are examples of this.

As a result, we can see the high expectations for the state's capacity to control events that are bound up with the development of transport systems involving automated vehicles. The scenarios expect that the state will cooperate with the private sector in developing the necessary technologies. This is accompanied by new legislation on licensing, insurance and liability, and acceptance-creating concepts on the topics of data management and standardization (open source, interface compatibility, data protection and security).

With regard to the population's acceptance of autonomous driving, it is clear that a series of possible factors could have a positive impact. Firstly, automated driving is combined with societal use of an efficient and environmentally friendly transport system. Secondly, it is quite possible that private users' and economic players' acceptance will rise in coming years, due to individual lifestyle and economic benefits, particularly when governments actively promote technology and acceptance.

A further factor that automation may positively impact is the prospect of cost-effective use and an upgrading of urban land use. One example is parking, for which automation promises clear cost-savings for the building of parking areas and, due to reduced space requirements, potential conversion to high-value usage. But areas on the edge of the city or in the surrounding area might also profit in the course of a potential revaluation of location-choice criteria, and from increased attractiveness as a place to live. 
It must, however, be borne in mind that there is much uncertainty concerning the factors mentioned here. Firstly, given the fundamental legal and ethical questions (see Chaps. 4 and 25), it is not at all possible to predict at what speed, and in what form, urban transport systems involving autonomous vehicles will be developed.

It is also currently not possible to reliably forecast the consequences for transport, and thus also urban land use. By integrating autonomous driving into a collective public transport system, carsharing may develop more strongly, and car ownership may fall. An increased acceptance and use of "one's own" car could strengthen the prospects of individual motorized transport. The latter case, in particular, raises the question of possible "rebound effects." Time savings and low usage costs may lead to higher mobility rates and increased kilometers traveled [22]. Under these circumstances, an increase in autonomous vehicles would compensate initial efficiency gains in the use of road capacity.

However, the question of how the amount of additional costs of autonomous-vehicle use might evolve currently remains unanswered. The scenarios analyzed in this chapter are not plausible on this point, arguing solely on the assumption that mobility will continue to be affordable in future. Calculations of the additional costs to equip cars, however, assume that both purchase and running costs will initially increase markedly [22, 28]. To these can be added resulting costs for municipalities for transport infrastructure adjustment and the building of new neighborhoods, should the attractiveness of suburbs actually increase.

Out of all these aspects follows much uncertainty in planning for local and regional stakeholders - the politicians, administrations, transport operators and the real estate sector. In particular, the adjustment of transport infrastructure and settlement development demands a long-term approach, including the corresponding regulation and financing. Changes in urban land use in the course of autonomous driving are thus only to be expected when most vehicles on the street are automated. So long as this is not the case, traffic density might well continue to increase significantly, journeys remain difficult to plan, parking demand stay high and street widths remain unaffected. Stakeholders, at least those from local traffic and urban planning departments, are thus currently still lacking important orientation for taking action and decisions. Not least among this is the lack of clarity as to what form autonomous driving will actually take in the medium and long term.

\subsection{Summary and Outlook}

The core aim of this article has been to fathom potential implications on urban form and land use of a transport system with autonomous vehicles, and to assess the way in which political and economic conditions might impact this development. Based on available scenarios and visions of "the city of tomorrow," and their ideas regarding integrating autonomous vehicles into transport systems, we have seen that different developments can be envisaged. For example, is the autonomous vehicle in the scenario a private one driven 
by an autopilot, unaided by any external system, or is it networked via vehicle-infrastructure communication? Or is it an integrated part of public transportation?

Depending on these varying characteristics, autonomous transport modes have the potential to change the transport system in utterly different ways. Their properties and potential uses will also affect land-use and urban planning. Areas of influence include parking demand and organization, and the attractiveness of neighborhoods as places to live, shop or work. Moreover, autonomous vehicles may allow land currently used for transport and parking to be converted to other uses (either for other transport uses, such as walking or cycling, but also for construction purposes). The changes that might actually follow depend largely on the direction in which autonomous driving evolves.

What aspects are essential to include in discussions on automated driving from an urban development and planning point of view?

Firstly, it is clear that autonomous driving may have a series of possible effects on urban land use that are relevant, in turn, as decision-making criteria for owning and using autonomous vehicles. The possibility of households achieving their "suburban" preferences more easily is one example of this. Connections in decision-making processes between long-term mobility (location choice) and daily mobility (destination and transport mode selection) should be brought into debates surrounding autonomous driving. As well as such individual-centered criteria, there are relevant issues in relation to autonomous driving's societal use. These involve, for example, the follow-up costs of developing new suburban neighborhoods as a result of changes in such areas' attractiveness. The extent to which such correlations actually materialize as autonomous driving is introduced, and how the consequences are to be assessed, should be understood and discussed in relation to autonomous driving as a matter of priority.

Secondly, there is the finding that, alongside potential changes in land use, far-reaching transformation-right down to new infrastructure and the reconfiguring of transport spaces including those for parking-may arise in the course of modifying the transport system. Developments in the driving patterns and handling of autonomous and non-autonomous vehicles, and also in other modes, must take this into account. That is altogether a long-term task, as changes in urban land use in the course of autonomous driving can only be expected when most vehicles on the street are automated [22]. Many of these questions need further investigation. There is, for instance, a need to analyze what impact autonomous driving might have on long-term plans for designing parking spaces, cycle lanes, junctions, sidewalks, cross-sectional road profiles etc of urban spaces. How can a successive transformation towards a transport system with autonomous vehicles be designed? What are plausible scenarios for its introduction in the first place? Requiring clarification here is not merely how the present infrastructure can be "converted," but also how the current prioritization and roles of various modes and transport means will change in the process. With the increase in autonomous vehicles and the emergence of special traffic lanes described above, there may be greater separation of functions between various modes. It may also become more difficult for other transport users to cross the street as a result of autonomous vehicles' dense traffic flow. This raises the question of on how much 
of an equal footing, the mix of the various transport-mode uses should be managed in future, as the impact of autonomous driving makes itself felt.

It is becoming clear that not only are urban development issues relevant to the debates on autonomous driving, but the reverse is also the case. Of great consequence is the impact that an automated transport system has on the concepts and objectives of urban planning and development. To what extent and under which conditions can a transport system with autonomous vehicles contribute to realizing currently valid models, such as dense and compact cities? Or will automation promote a return to cities built around the automobile? What is the relationship between urban-planning elements for structuring autonomous transport and the demands of the universally aspired-to city of pedestrians, cycling and rail? Could it be, under the impact of autonomous driving, that we need to formulate fundamentally different or new models for the development of cities? We can now start the discussion of these questions.

Open Access This chapter is distributed under the terms of the Creative Commons Attribution 4.0 International License (http://creativecommons.org/licenses/by/4.0/), which permits use, duplication, adaptation, distribution and reproduction in any medium or format, as long as you give appropriate credit to the original author(s) and the source, a link is provided to the Creative Commons license and any changes made are indicated.

The images or other third party material in this chapter are included in the work's Creative Commons license, unless indicated otherwise in the credit line; if such material is not included in the work's Creative Commons license and the respective action is not permitted by statutory regulation, users will need to obtain permission from the license holder to duplicate, adapt or reproduce the material.

\section{References}

1. Cervero, R. und Kockelman, K. (1997): Travel demand and the 3Ds: Density, diversity, and design. In: Transportation Research Part D: Transport and Environment, Volume 2, Issue 3, September 1997, pp. 199-219. DOI: 10.1016/S1361-9209(97)00009-6. URL: http://www. sciencedirect.com/science/article/pii/S1361920997000096

2. Apel, D. (2003): Der Einfluss der Verkehrsmittel auf Städtebau und Stadtstruktur. In: Bracher, T. ; Haag, M. ; Holzapfel, H. ; Kiepe, F. ; Lehmbrock, M. ; Reutter, U. (Ed.): HKV - Handbuch der kommunalen Verkehrsplanung (Chapter 2.5.7.1).

3. RAND Corporation (2014): Autonomous Vehicle Technology. A Guide for Policymakers. URL: http://www.rand.org/pubs/research_reports/RR443-1.html

4. Wilson, I. H. (1978): Scenarios. In: Fowles J. und Fowles, R. B. (Ed.): Handbook of Futures Research. Greenwood Pub Group Inc, Westport und London, pp. 225-247.

5. von Reibnitz, U. (1992): Szenario-Technik. Instrumente für die unternehmerische und persönliche Erfolgsplanung. Gabler Verlag, Wiesbaden.

6. Steinmüller, K. H. (1997): Grundlagen und Methoden der Zukunftsforschung - Szenarien, Delphi, Technikvorausschau. WerkstattBericht 21. Sekretariat für Zukunftsforschung. Gelsenkirchen. URL: http://steinmuller.de/media/pdf/WB\%2021\%20Grundlagen.pdf

7. Foresight Directorate (2006): Intelligent infrastructure futures. The Scenarios - Towards 2055 URL: http://www.bis.gov.uk/assets/foresight/docs/intelligent-infrastructure-systems/the-scenarios2055.pdf 
8. Fraunhofer Gesellschaft zur Förderung der Angewandten Forschung e.V. (2012): Visionen zur Morgenstadt. Leitgedanken für Forschung und Entwicklung von Systeminnovationen für nachhaltige und lebenswerte Städte der Zukunft. URL: http://www.morgenstadt.de/de/_jcr_content/stage/ linklistPar/download/file.res/Fraunhofer_Visionen\%20zur\%20Morgenstadt_050212.pdf

9. Stadt Wien (Magistrat 18 der Stadtentwicklung und Stadtplanung) (2012): smart city Wien towards a sustainable development of the city (= Blue Globe ReportSmartCities \#1/2012) URL: http://www.smartcities.at/assets/Projektberichte/Endbericht-Langfassung/BGR01-2012K11NE2F00030-Wien-v1.0.pdf

10. Federal Ministry for Education and Research (n.D.): Morgenstadt - eine Antwort auf den Klimawandel.

11. Promotorengruppe Mobilität der Promotorengruppe Mobilität Wirtschaft - Wissenschaft (2013): Abschlussbericht der Promotorengruppe Mobilität. URL: http://www. forschungsunion.de/pdf/mobilitaet_bericht_2013.pdf

12. Forum for the Future (2010): Megacities on the move. Your guide to the future of sustainable urban mobility in 2040. URL: http://www.forumforthefuture.org/sites/default/files/images/ Forum/Projects/Megacities/megacities_full_report.pdf

13. Angel et al. 2011: Making Room for a Planet of Cities. Lincoln Institute of Land Policy. Cambridge, MA.

14. Fagnant, D. J. und Kockelmann, K. M. (2013): Preparing a Nation for Autonomous Vehicles: Opportunities, barriers and Policy Recommendations. Eno Foundation. URL: http://www. enotrans.org/wp-content/uploads/wpsc/downloadables/AV-paper.pdf

15. Irmscher, I. (n.D.): Benutzerfreundliche automatische Parksysteme - Besondere Anforderungen Planung - Einsatz. URL: www.givt.de/index.php/de/component/jdownloads/finish/4/22

16. Kowalewski, S. (2014): Überlassen Sie das Parken Ray. Deutschlandradio Kultur. URL: http:// www.deutschlandradiokultur.de/technologie-ueberlassen-sie-das-parken-ray.2165.de.html? dram:article_id $=290092$

17. Mitchell, W.J., Boronni-Bird, E., Burns, L.D. (2010): Reinventing the Automobile. Personal Urban Mobility for the $21^{\text {st }}$ Century. The MIT Press. Cambridge, MA.

18. LEG Stadtentwicklung GMBH (2008): Mobilitätshandbuch Zukunftsstandort Phoenix West. Dortmund.

19. Continental AG (2014): Der Fahrer entscheidet, das Auto übernimmt. URL: http://www.contionline.com/www/automotive_de_de/themes/passenger_cars/automated_driving

20. Audi (2012): Automatisch ins Parkhaus. URL: http://blog.audi.de/2012/09/21/automatisch-insparkhaus/

21. Litman, T. (2014): Ready or waiting. Traffic Technology International. January. 37-42. URL: http://www.traffictechnologytoday.com

22. Litman, T. (2014): Autonomous Vehicle Implementation Prediction. Implications for Transport Planning. June 4, 2014. URL: http://www.vtpi.org/avip.pdf

23. Le Vine, S. und Polack, J. (2014): Automated Cars: A smooth ride ahead? ITC Occasional Paper-Number Five, February 2014. URL: http://www.theitc.org.uk/docs/114.pdf

24. Angerer, F. \& Hadler, G. (2005): Integration der Verkehrs- in die Stadtplanung. In: : Steierwald, G.; Künne, H. D. \& Vogt, W. (Ed.): Stadtverkehrsplanung. Grundlagen, Methoden, Ziele. 2. Auflage, Springer-Verlag. Berlin, Heidelberg. pp. 18-28.

25. Guth, D.; Siedentop, S. \& Holz-Rau, C. (2012): Erzwungenes oder exzessives Pendeln? Zum Einfluss der Siedlungsstruktur auf den Berufspendelverkehr. In: Raumordnung und Raumforschung (2012) 70, pp. 485-499. URL: http://link.springer.com/article/10.1007\% 2Fs13147-012-0196-5 
26. Destatis (Statistisches Bundesamt) (2014): Berufspendler: Infrastruktur wichtiger als Benzinpreis. Article from May 6, 2014. URL: https://www.destatis.de/DE/Publikationen/ STATmagazin/Arbeitsmarkt/2014_05/2014_05Pendler.html\#Link3

27. McKenzie, B. (2014): Modes Less Traveled-Bicycling and Walking to Work in the United States: 2008-2012. American Community Survey Reports. URL: http://www.census.gov/hhes/ commuting/

28. Silberg, G., Wallace, R., Matuszak, G. (2012): Self-Driving Cars: The Next Revolution, KPMG and the Centre for Automotive Research; URL: www.kpmg.com/Ca/en/IssuesAndInsights/ ArticlesPublications/Documents/self-driving-cars-next-revolution.pdf

29. Häfner, S., Rapp, H., Kächele, H. (2012): Psychosoziale Belastungen von Bahnpendlern und was soll man tun? In: Psychotherapeut 2012 (57): 343-351

30. Lewis, D. (2004): Commuters suffer extreme stress, in BBC, URL: http://news.bbc.co.uk/2/hi/ uk_news/4052861.stm

31. Fernandes, P. (2012): Platooning With IVC-Enabled Autonomous Vehicles: Strategies to Mitigate Communication Delays, Improve Safety and Traffic Flow. URL: http://home.isr.uc.pt/ $\sim$ pedro/T-ITS-11-02-0065.pdf

32. Brownell, C. K. (2013): Shared Autonomous Taxi Networks: An Analysis of Transportation Demand in NJ and a 21st Century Solution for Congestion. URL: http://orfe.princeton.edu/ $\sim$ alaink/Theses/2013/Brownell,\%20Chris\%20Final\%20Thesis.pdf

33. Brownell, C. K. \& Kornhauser, A. (2013): Autonomous Taxi Networks: a fleet size and Cost Comparison between two emerging transportation models and the conventional automobile in the state of New Jersey. URL: http://orfe.princeton.edu/ alaink/TRB'14/TRB'14_ BrownellPaper_0728v2.pdf

34. Gorton, M. (2008): Using Information Technology to Achieve a Breakthrough in Transportation in New York City. The Open Planning Project. August 2008. URL: http://www.streetsblog.org/ wp-content/pdf/SmartParaTransit.pdf 